\title{
INDUSTRIALly USABLE NUMERICAL CALCULATION-BASED METHOD FOR ESTIMATING RESIDUAL STRESS DUE TO LASER CLADDING REFURBISHMENT
}

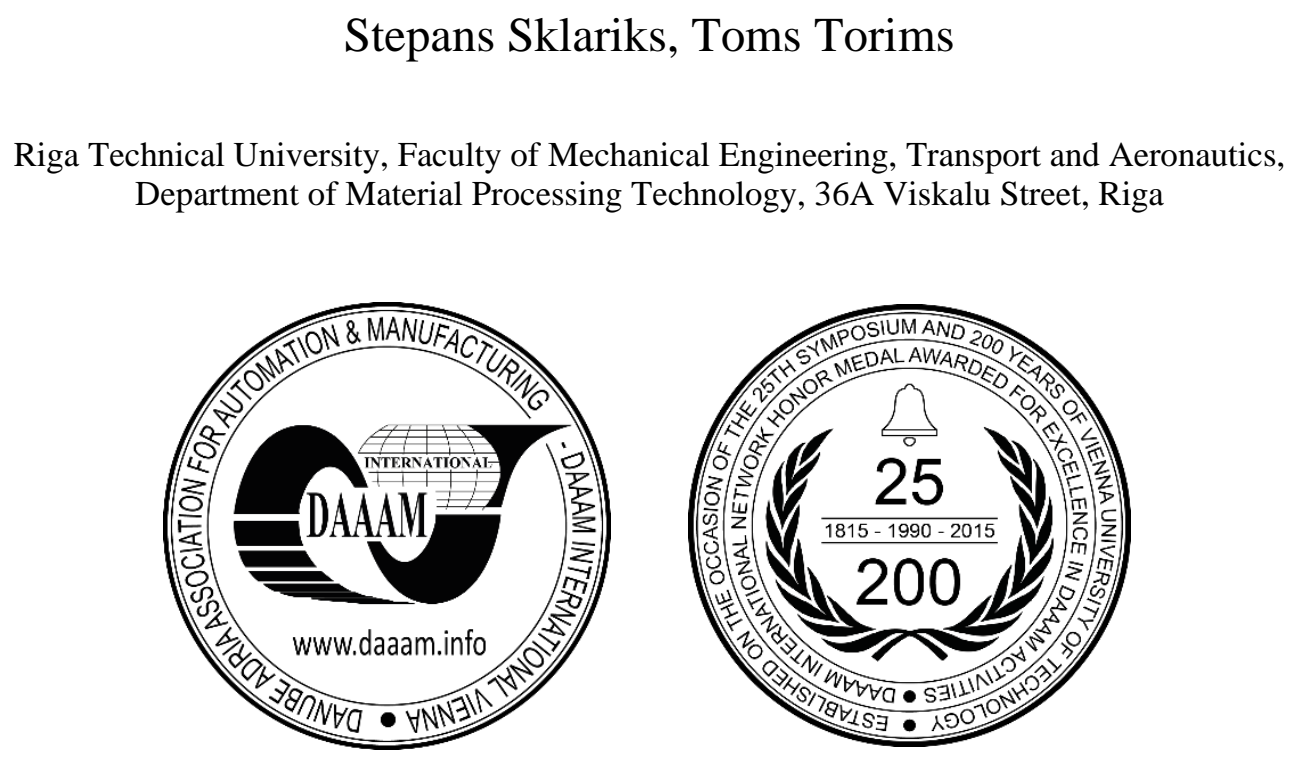

This Publication has to be referred as: Sklariks, S[tepans] \& Torims, T[oms] (2017). Industrially Usable Numerical Calculation-Based Method for Estimating Residual Stress due to Laser Cladding Refurbishment, Proceedings of the 28th DAAAM International Symposium, pp.0529-0536, B. Katalinic (Ed.), Published by DAAAM International, ISBN 9783-902734-11-2, ISSN 1726-9679, Vienna, Austria

DOI: $10.2507 / 28$ th.daaam.proceedings.075

\begin{abstract}
The current paper forms part of a series of research activities investigating the potential to implement a novel mobile device for marine diesel engine crankshaft journal surface refurbishment using laser cladding technology. Currently the laser cladding renovation process is not yet certified and is not an approved repair method for parts with highly stressed zones such as the fillets and bearing surfaces of marine diesel engine crankshafts, due to data deficiency or the absence of a validated method to evaluate high residual stress formation. In the current work, a method is proposed based on 3D transient temperature, calculating the residual stress field in the laser cladding model. The industrial application advantages of such a method are discussed and demonstrated in a case study. Further research campaigns and actions for demonstrating the industrial suitability of this method are discussed.
\end{abstract}

Keywords: Laser cladding; Marine Diesel Engine Crankshaft; Refurbishment Technology; Numerical Calculation; Transient Temperature Field; Transient Residual Stress Field.

\section{Introduction}

Laser cladding can provide a permanent structural repair and refurbishment of high-value components made of alloys that are generally considered unweldable, due to the small heat-affected zone, rapid solidification, improved cleanness and lower dilution, as well as greater control over the depth of the heat-affected zone. [1] [2] 
The use of such technology would prove highly beneficial when integrated within a mobile device described in [3] and applied in the renovation of marine diesel engine crankshaft journals. According to [4] and [5], considerable economic benefits and saving of valuable time can be achieved by utilizing this kind of technological arrangement for marine diesel engine repairs. In [6] a prototype of such device was made and one of the biggest challenges for the implementation of this kind of device was established. In the view of several well-known classification societies the utilization of laser cladding technology as a repair method for crankshafts, especially in highly stressed zones such as fillets and bearing surfaces is not acceptable due to a high risk that the heat-affected zone could produce excessive hardness resulting in detrimental residual stress. The authors of the current work believe that such a view is based upon purely precautionary measures due to the thermomechanical nature of the process, the use of which indeed carries the risk of detrimental residual stress formation, however no quantifiable data is provided as justification.

It has been established that a numerical simulation method is a cost-effective technique to evaluate thermal history, evolution of residual stresses and distortions during the laser cladding process, which therefore make it possible to optimize process parameters without physically utilizing the technology. [7] Placing this conclusion in the context of marine diesel engine in-situ laser cladding technology development, numerical simulation therefore becomes an appropriate quantifiable means of establishing the level of residual stresses in the renovated section of the repaired part. Providing quantifiably justified means of risk evaluation for the certification of such technology would allow its further industrial implementation Hence, our current work is aimed at choosing the most appropriate laser cladding numerical simulation approach that would be efficient in terms of provision of necessary data on the levels of residual stress, while being industrially acceptable in terms of operational complexity and execution time.

\section{Method Description}

The method developed within this work is based on numerical simulation techniques, the most notable from the perspective of the present paper's authors being the laser cladding residual stress simulation model developed by Kovacevic et al. in [7], Bruckner et al. in [8] as well as Morville S. in [9] with negligible experimentally evaluated error where data on such evaluation was available. The current work utilizes all the fundamental laser cladding numerical simulation principles given in the aforementioned sources.

It is the authors' opinion that the main issue in all of the aforementioned works as well as other numerical studies is the level of complexity of the model setup and recreation of the results, requiring in-depth knowledge of the physical process that is being simulated and the method to simulate it. This considerably limits the use of such predictive tools to real-life scenarios, due to the need for qualified personnel to perform the operator's work, i.e. setting up the proposed mobile laser cladding device.

Another limitation is the significant time cost of performing such a laser cladding numerical simulation, where some complex simulation tools like the one developed in [9] can even take up to 3 months to execute.

Thus, despite the valuable and precise insight they provide on the modelled process, they cannot be considered industrially usable because of the two underlying factors explained above. This paper proposes an automated, simplified laser cladding model solution, in an attempt to eliminate these disadvantages.

For the successful development of the numerical simulation model, all the governing equations of the process first have to be established.

\subsection{Thermal equilibrium equation}

In the case of laser cladding process which can be modelled as thermo-mechanical coupled system, the thermal equilibrium equation can be written as:

$$
\rho c\left(\frac{\partial T}{\partial t}+v_{x} \frac{\partial T}{\partial x}+v_{y} \frac{\partial T}{\partial y}+v_{z} \frac{\partial T}{\partial z}\right)=\cdots+\frac{\partial}{\partial x}\left(\frac{K_{x} \partial T}{\partial x}\right)+\frac{\partial}{\partial y}\left(K_{y} \frac{\partial T}{\partial y}\right)+\frac{\partial}{\partial z}\left(K_{z} \frac{\partial T}{\partial z}\right)
$$

Where:

$K_{x x}, K_{y y}, K_{z z}-$ Conductivity in the element $\mathrm{x}, \mathrm{y}$ and $\mathrm{z}$ directions respectively;

$\rho$ - Density of material;

$c$ - Specific heat;

$T$ - Temperature of the material;

$v_{x}, v_{y}, v_{z}$ - Mass transport of heat;

$q$ - heat generation rate per unit volume.

\subsection{Stress - strain relationship}

The stress is related to strains by: 
$\{\sigma\}=[D]\left\{\varepsilon^{e l}\right\}$

Where:

$$
\begin{aligned}
& \{\sigma\}-\left[\sigma_{x} \sigma_{y} \sigma_{z} \sigma_{x y} \sigma_{y z} \sigma_{x z}\right]^{T} \text {-stress vector; } \\
& {[D]-\text { elasticity or elastic stiffness matrix or stress-strain matrix; }} \\
& \left\{\varepsilon^{e l}\right\}=\{\varepsilon\}-\left\{\varepsilon^{t h}\right\}-\text { elastic strain vector; } \\
& \{\varepsilon\}=\left[\varepsilon_{x} \varepsilon_{y} \varepsilon_{x y} \varepsilon_{y z} \varepsilon_{x z}\right]^{T} \text { total strain vector; } \\
& \left\{\varepsilon^{t h}\right\}-\text { total strain vector. }
\end{aligned}
$$

For the 3-dimensional case, the thermal strain vector is:

$$
\left\{\varepsilon^{t h}\right\}=\Delta \mathrm{T}\left[\alpha_{X}^{S E} \alpha_{y}^{S E} \alpha_{z}^{S E} 000\right]^{T}
$$

Where:

$$
\begin{aligned}
& \alpha_{X}^{S E} ; \alpha_{Y}^{S E} ; \alpha_{Z}^{S E}-\text { secant coefficient of thermal expansion in the } \mathrm{x}, \mathrm{y}, \mathrm{z} \text { direction; } \\
& \Delta T=T-T_{\text {ref }} ; \\
& T \text { - current temperature at the point in question; } \\
& T_{\text {ref }} \text { - reference (strain-free) temperature. }
\end{aligned}
$$

\subsection{Boundary Conditions}

Four types of boundary conditions are considered. It is presumed that these cover the entire element.

1. Specified temperatures acting over the surface:

$$
T=T^{*}
$$

2. Specified heat flows acting over the surface are modelled as a travelling 2-dimensional distributed heat source with a Gaussian distribution:

$$
q^{*}=\frac{3 q_{l}}{\pi R^{2}} \exp \left(-\frac{3\left(\mathrm{X}^{2}+(Y-v t)^{2}\right)^{2}}{R^{2}}\right)
$$

3. Specified convection acting over the surface (Newton's law of cooling):

$\{q\}^{T}\{n\}=h_{f}\left(T_{S}-T_{B}\right)$

4. Radiant energy loss:

$$
\begin{aligned}
& Q_{i}=A_{i} \varepsilon_{i} F_{i j}^{\prime} \sigma\left(T_{i}^{4}-T_{j}^{4}\right) \\
& F_{i j}^{\prime}=\frac{F_{i j}}{F_{i j}(1-\varepsilon)+\varepsilon_{i}}
\end{aligned}
$$

\section{Where:}

$T^{*}$ - specified temperature;

$\{n\}$ - unit outward vector;

$q^{*}$ - specified heat flow;

$\mathrm{T}_{\mathrm{B}}$ - bulk temperature of the adjacent fluid;

$T_{S}$ - temperature at the surface of the model;

$h_{f}-$ film coefficient evaluated at $\frac{T_{B}+T_{S}}{2} ;\left[\frac{W}{m^{2} K}\right]$

$\varepsilon_{i}$ - effective emissivity of surface i;

$F_{i j}$ - Radiation view factors; 


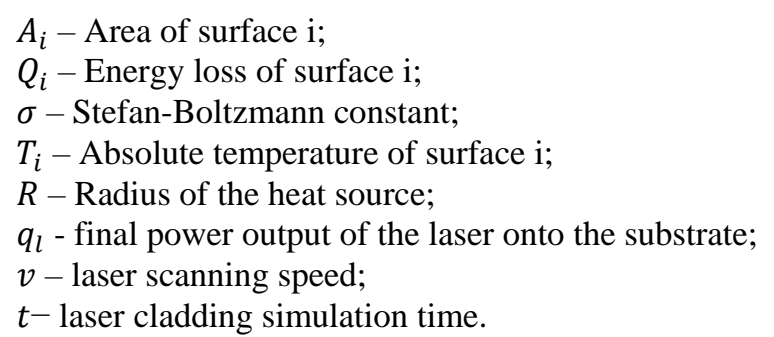

\subsection{Modelling procedure and assumptions}

The governing equations are solved with the FEM transient analysis procedure using commercial FEM software ANSYS APDL software.

The unique feature of the current model is that it provides a good indication of the melt pool shape, as well as the temperature-stress-strain history, considering material phase transformation and transformation plasticity during 1 cladding pass heating, whilst requiring a relatively low computation time and resources. The temperature field and stressstrain time-history calculations are obtained through an automated process, where the operator of the model enters the parameters of the workpiece geometry, laser heat source power, laser spot diameter and laser scanning speed, along with the selected workpiece material. Automated calculation is ensured by a script written in ANSYS APDL software which can be executed by opening the script with the appropriate parameters for the process being modelled.

However, the current model does not consider the influence of bead geometry on the temperature-strain distribution, which inarguably is very important when the aim is to obtain a precise mechanical response for the thermal contraction behavior of the consumable process materials. Additionally the current model does not take into account the gas/melt pool interaction, laser attenuation by powder, Bénard-Marangoni convection or a more precise laser beam mode heat source for the CO2, Nd:YAG and HPDL laser. The inaccuracy of the results in the model thus offer a subject for further improvement. However, the low time and computational resource cost will be gradually eroded as further improvements of the model are made.

\section{Case Study}

\subsection{Boundary Condition Data Entry}

Fig. 1. gives a schematic representation of the geometry model used within the current work.

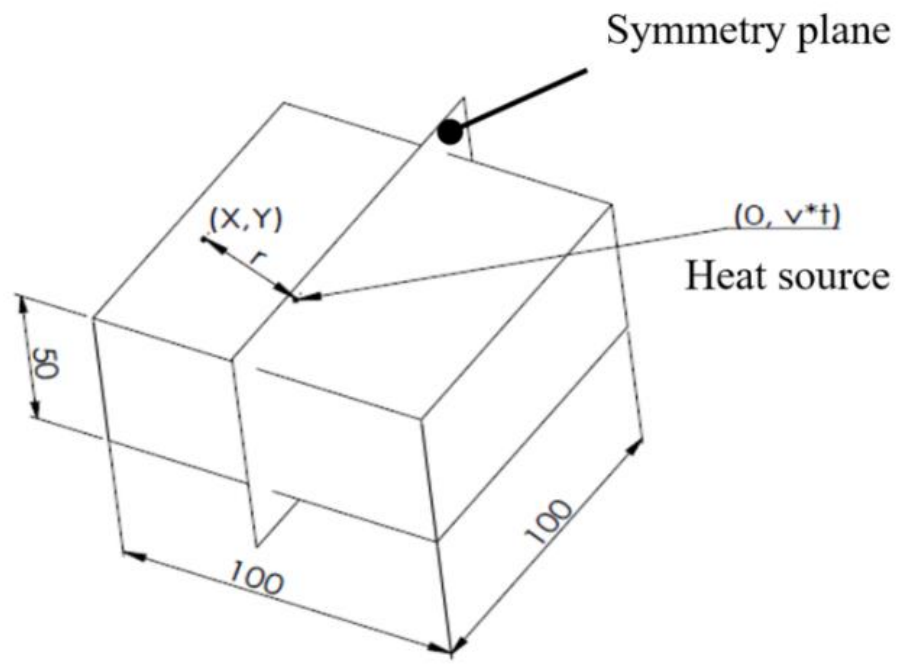

Fig. 1. Geometry of a modelled workpiece

To reduce the real-time simulation of the current process model, a symmetry plane for the symmetry boundary condition is introduced, as illustrated in Fig. 1.

The substrate material was modelled as C45. Given the very wide range of temperatures involved in the laser cladding process, the accuracy of a model strongly correlates with the precise definition of all non-linearities associated with the material mechanical property changes that are caused by temperature change. According to the standard DIN EN 100832 - technical delivery conditions for non-alloy steels [10] as well as the technical material specifications for C45 provided by some of the best-known steel suppliers [11] [12], all the material properties as time functions are defined accordingly. 
To successfully consider the phase transformation phenomenon, various temperature-dependent thermo-physical material properties must be defined, such as density, Young's module, thermal expansion thermal conductivity, specific heat and Poisson's ratio. The defined model considers transformation plasticity. A simple method to define a material model with transformation plasticity is to define the bilinear stress-strain curve, which assumes the isotropic hardening of the material.

For the definition of the current model, two basic elements that were defined with "ANSYS" software are used: PLANE55 and SOLID 70. [13]
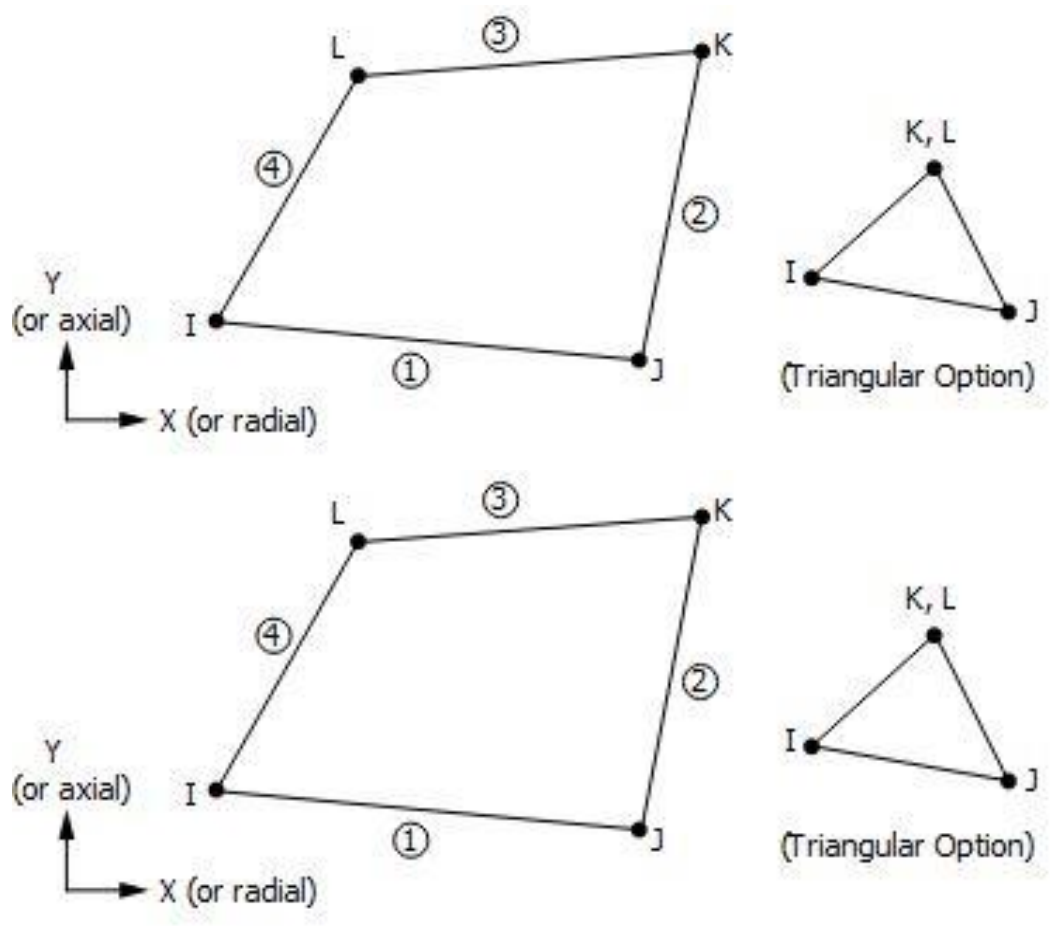

Fig. 2. PLANE55 and SOLID70 element geometry [13]

The initial temperature for the boundary conditions defined in (4) was chosen as per NTP (Normal temperature and pressure), which is $20^{\circ} \mathrm{C}$. Table 1 defines the technological parameters of the process to be modelled for the boundary condition given in (5).

\begin{tabular}{|l|c|}
\hline$P$ - final power output of the laser onto the substrate, $[W]$ & 700 \\
\hline$R$ - radius of the laser spot, $[\mathrm{mm}]$ & 1 \\
\hline$v$ - laser scanning speed, $\left[\frac{\mathrm{m}}{\mathrm{s}}\right]$ & 10 \\
\hline
\end{tabular}

Table 1. Technological equipment parameter chosen for the current numerical study

The convective heat transfer coefficient for all the surfaces of the modelled workpiece was chosen to be $h_{f}=30 \frac{\mathrm{W}}{\mathrm{m}^{2} \mathrm{~K}}$, which is acceptable for normal ventilated in-laboratory conditions according to [14] and [15] which is later used for the boundary condition given in (6).

And finally, based on the information regarding the emissivity of various materials found in [16], the effective emissivity of the material $\mathrm{C} 45$ is chosen to be $\varepsilon_{i}=0.94$.

\subsection{Results}

The numerical calculations performed within the scope of this work as mentioned previously were achieved using "ANSYS r16" FEM software. The numerical calculation consists of 2 major parts:

1. Obtaining the time-dependent temperature fields of the current study;

2. Reading the results of the first parts of this study and iteratively entering them within the second part of the study, to obtain the mechanical stress-strain response of the material model. 
Given the iterative nature of the calculations described above, the scriptable "ANSYS r16 Mechanical APDL" part of the software had to be used, thus developing an automated numerical calculation tool to be used by the device operator mentioned in the introductory part of this paper.

The simulation was run on a regular office laptop.

The temperature field results obtained at different time intervals are given in fig. 3 . The results obtained in the current sample numerical simulation indicate that the material is locally heated up to $2,451^{\circ} \mathrm{C} @ t=0.2 \mathrm{~s}, 3,870{ }^{\circ} \mathrm{C} @ t=5 \mathrm{~s}$ and even reaches the temperature value of $4,132^{\circ} \mathrm{C} @ t=10 \mathrm{~s}$. But the most important information that our simulation can provide regarding the temperature field is an estimation of the weld pool size during the process, which gives weld pool measurements: depth $=1.56 \mathrm{~mm}$ and radius $=1.15 \mathrm{~mm}$ (diameter $=2.3 \mathrm{~mm}$ ). This information can offer an insight into the various output parameters of the clad, such as its width and depth, as well as the height and width of the heat-affected area and dilution zone.
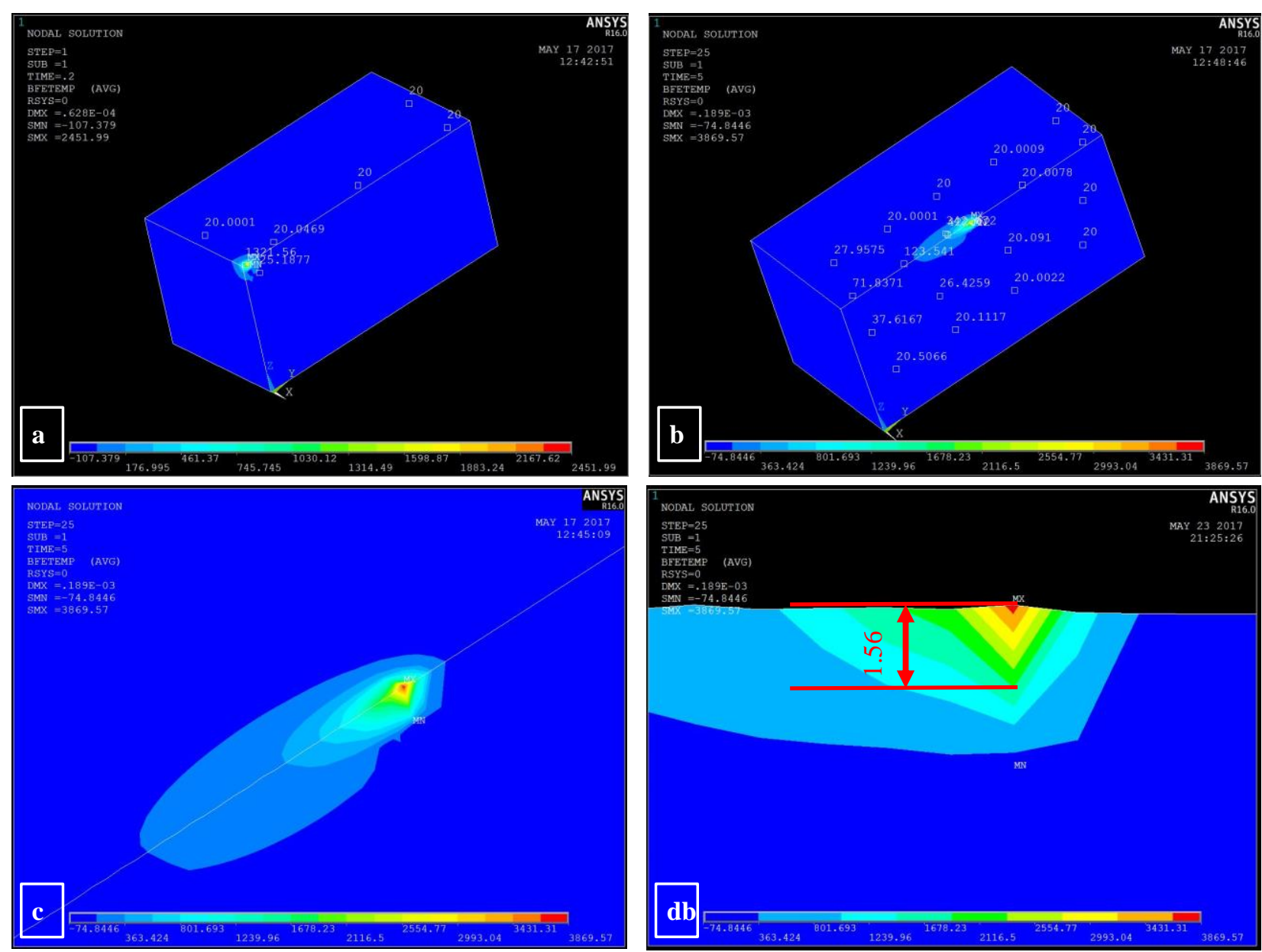

Fig. 3. Temperature field results at (a) $t=0.2 s$; (b) $t=5 s$; (c) Expanded view of the heat source at $t=5 s$; (d) Expanded view of the heat source at $\mathrm{t}=5 \mathrm{~s}$ with depth measurement

In fig. 4, the residual stress field is shown at different time intervals. The results obtained here are particularly important for the specific aim of this work, which is to implement the laser cladding technology for the renovation of marine diesel-engine crankshafts. The von Mises stress field obtained here can be used to identify the safety margin between the operational stresses and ultimate stresses of the $\mathrm{C} 45$, which according to [11] is $620 \mathrm{MPa}$. Comparing this value with the values obtained in the study, the maximum residual stresses with the technological parameters specified within this study do not exceed $220 \mathrm{MPa}$, thus it can be deduced that there is a substantial safety margin of $\Delta=620-$ $220=400 M P a$ which indicates that the risk of rupture or cracking of the material is almost non-existent.

It is acknowledged that the geometry of the clad as well as the material properties which are used for the coating are important parameters for determining a more realistic situation of cracking due to residual stresses. However, with only limited computer and time resources available for the evaluation of residual stresses, which is the case in typical operative field situations, the current model can be used to obtain results separately for the substrate and for the clad geometry, defining separately all the material and boundary conditions. In this way, the current model provides operational simplicity, speed and efficiency, which are very important in operational field conditions. 

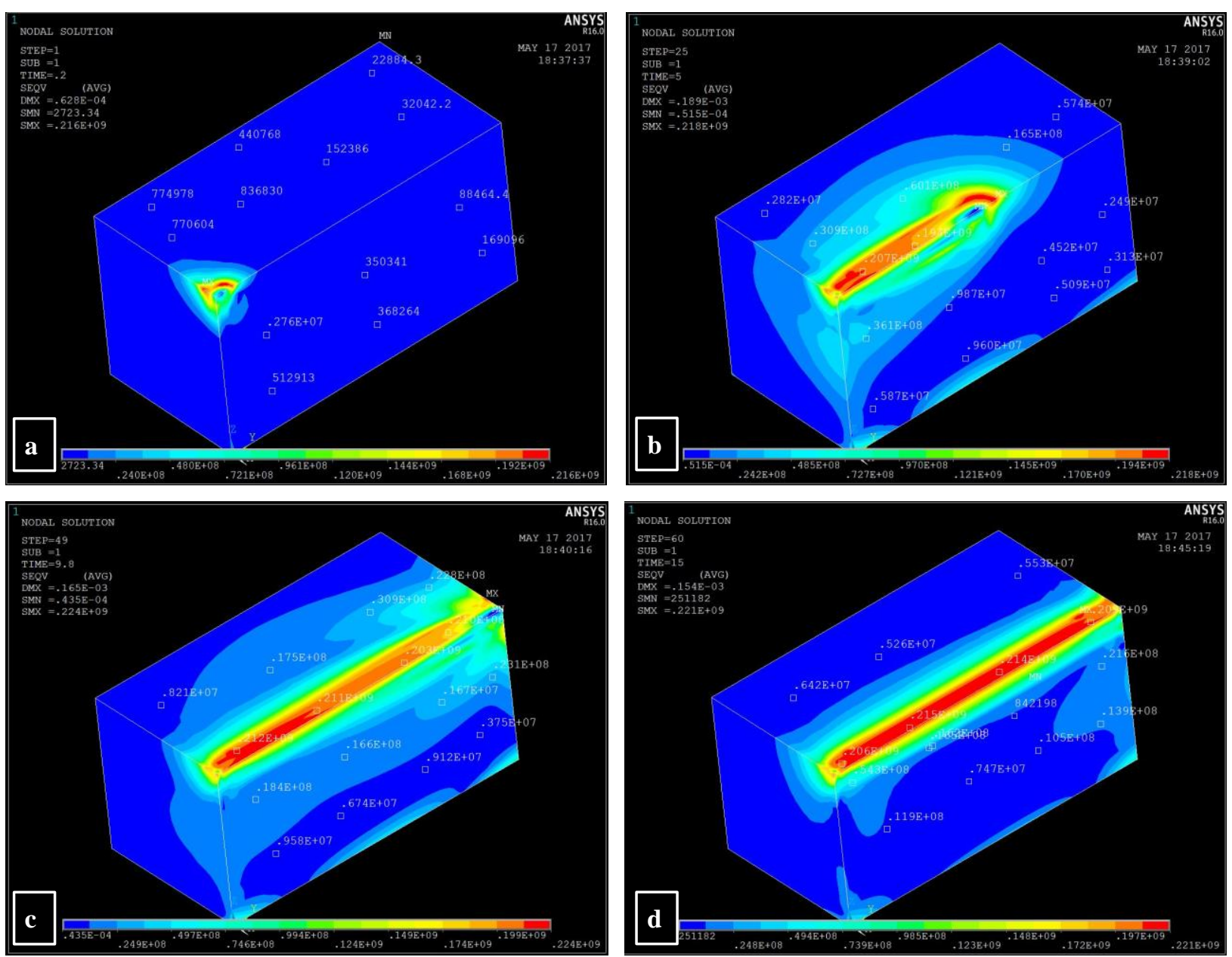

Fig. 4. Residual stress field results at (a) $t=0.2 \mathrm{~s}$; (b) $\mathrm{t}=5 \mathrm{~s} ;$ (c) $\mathrm{t}=9.8 \mathrm{~s} ;$ (d) $\mathrm{t}=15 \mathrm{~s}$.

\section{Conclusions}

Within the previous research efforts, it has been established that laser cladding technology is highly suitable for the application of marine diesel-engine crankshaft journal surface renovation in terms of the technological requirements of the resultant product, technology precision, repeatability and in-situ capability. However, a significant limitation on its real-life application exists, due to the complex nature of the laser cladding process, which has a great number of input and process parameters, along with the high sensitivity of these process parameters, which give rise to a detrimental residual stress within the renovated work.

To address the problem above, a novel script-written automated simulation tool was developed using FEM ANSYS software, which would enable a relatively quick and simple main process parameter study to be performed providing an insight for the in-situ laser cladding device operator into the levels of residual stress in renovated work. The scripted FEM tool limits the user input to such a level, that only the most important material properties, laser cladding technology and technological conditions are to be entered, while the rest of calculations are performed automatically, thus decreasing workload time-consumption and qualification requirements imposed on the intended user.

Experimental validation of the model utilized within the current work will be performed in future research campaigns to determine the accuracy of calculations made. Additional effort is required to achieve gas/melt pool interaction, laser attenuation by powder, Bénard-Marangoni convection and a more precise laser beam mode heat source integration within the tool developed in current work, while keeping the calculation time-cost and user workload to the same or even lower level.

\section{References}

[1] Toyserkani, E.; Khajepour A. and Corbin, S. (2005). Laser Cladding., CRC Press LLC, ISBN: 0-8493-2172-7. Florida

[2] Torims, T. (2013). The Application of Laser Cladding to Mechanical Component Repair, Renovation and Regeneration. Riga : DAAAM International, ISBN: 978-3-901509-94-0. 
[3] Torims T. (2013). Laser cladding device for in-situ repairs of marine crankshafts. Advanced Materials Research Vols. 712-715., pp 709-714., DOI:10.4028/www.scientific.net/AMR.712-715.709

[4] Torims, T.; Vilcans, J.; Zarins, M.; \& Ratkus, A. (2012). Development of the In-Situ Laser Renovation Technology for Marine Diesel Engine Crankshafts. ISBN 978-3-901509-91-9, ISSN 2304-1382, pp 0009 - 0014, Published by DAAAM International, Vienna, Austria.

[5] Torims, T.; Bruckner F.; Ratkus, A.; Fokejevs A.; Logins, A. (2014). The Application of Laser Cladding to Marine Crankshaft Journal Repair and Renovation, Proceedings of the ASME 2014 12th Biennial Conference on Engineering Systems Design and Analysis., Copenhagen

[6] Torims, T; Pikurs, G; Ratkus A.; Logins A.; Vilcans J.; Sklariks S. (2014). Development of Technological Equipment to Laboratory Test In-Situ Laser Cladding for Marine Engine Crankshaft Renovation, 25th DAAAM International Symposium on Intelligent Manufacturing and Automation, DAAAM, Elsevier Ltd., pp. 559-568., DOI: $10.1016 /$ j.proeng.2015.01.405

[7] Farahmand, P.; Kovacevic R. (2014). An experimental-numerical investigation of heat distribution and stress field in single and multi-track laser cladding by a high-power direct diode laser. Dallas : Elsevier, Vol. 63. 0030-3992.

[8] Bruckner, F.; Lepski, D. and Beyer, E. (2006). Modelling the Influence of Process Parameters and Additional Heat Sources on Residual Stresses in Laser Cladding. Dresden, ASM International.

[9] Morville, S. (2012). Modelisation multiphysique du procede de Fabrication Rapide par Projection Laser en vue d'ameliorer l'etat de surface. Universite de Bretagne Sud, NNT : 2012LORIS280>.

[10] Deutsche Norm. (2006). Steels for quenching and tempering - Part 2: Technical delivery condition for non-alloy steels English version of DIN EN 10083-2:2006-10. DIN EN 10083-2.

[11] Group. (2017). Quality of C45E. s.1. : Lucefin Group.

[12] Saarstahl (2017). Material Specification sheet of C45. s.1..

[13] ANSYS INC. (2017). ANSYS Mechanical APDL Help Theory reference Heat flow fundamentals section. Southpointe.

[14] http://www.engineeringtoolbox.com/convective-heat-transfer-d_430.html (2017) The engineering toolbox. Convective Heat Transfer. The engineering toolbox. The engineering toolbox. Accessed on: 05 14, 2017.

[15] http://www.engineersedge.com/heat_transfer/convective_heat_transfer_coefficients_13378.htm, .Engineer's Edge. Convective Heat transfer coefficients table chart. Accessed on: 05 14, 2017.]

[16] MIKRON Vertretung Schweiz. (2012) Table of Emissivity of various surfaces. 